\title{
THE EFFECTS OF APPLYING COMMUNICATION TOOLS BASED ON CONNECTIVISM THEORY ON STUDENTS' ACADEMIC ACHIEVEMENT AND THE VALUE OF THEIR ENGAGEMENT
}

\author{
Leili Lajmiri \\ M.A in Educational Sciences, Instructional Technology, Faculty of Psychology and Educational \\ Sciences, Islamic Azad University, Tehran South Branch \\ LajmiriLeili@,Yahoo.com
}

\begin{abstract}
Today, with the increase in communication means and their impact on learning, educational environment is changing. The aim of the present study was to investigate the use of communication tools based on connectivism theory on students' academic achievement and the value of their engagement. The statistical population of the study consisted of the students studying as sophomore in high school, district 3, Tehran City. In this study, sampling method was "available sampling" and two 15 -students classes formed the experimental and control group. This research was based on a quasiexperimental design, pretest, posttest, and follow-up with the control group. The experimental group was treated by teaching chemistry through a website while the control group was treated by teaching chemistry traditionally. The treatment continuously lasted for three days a week for a semester. The tools to gather the required data include survey test of students' engagement in high school and the questionnaire prepared by the researcher for chemistry lesson. ANOVA test with repeated measures was used to analyze data. The results obtained indicated learning stability and confirmed there was a significant difference between students' scores in different time periods of measurement in experimental group and. According to the results, teaching by the use of communication means in addition to showing a significant difference with the traditional method of teaching has a positive and significant effect on chemistry lesson; however, no significant differences were seen in students' engagement in the two groups.
\end{abstract}

Keywords: communication means, connectivism theory, students' engagement, learning

\section{INTRODUCTION}

Great changes in technology and knowledge were occurred in the last centuries especially in the last few decades. The scope of these changes has run modern societies of education system into new challenges. Researchers and trainers in response to new conditions have come up with variety of theories and models to solve the new challenge. In 2004 Siemens drew the world's attention into a new paradigm to meet the challenges of the digital age by introducing connectivism theory. $\mathrm{He}$ believes that connectivism theory is a proper and timely response to the present situation of society and its current technologies.

In connectivism theory, knowledge is distributed within a network of people and things and learning is the process of connecting, growing and directing the networks (Siemens, 2004). Today, teaching space is changing due to the growth of communication means and their impact on learning. Research findings suggest that each of these communication media can alone have effects on students' learning and engagement. For example, Miller (2011) has shown that the use of social networking tools increases interaction in learning, collaborative learning and the skills of the 21 st century. In a study conducted by Lei, Krilavicius, Zhang, Wan and Man (2012) on using web to promote learning in higher education, it was shown that teaching using web technologies facilitates teaching and learning. Using social networks like Facebook to share content, experiences and news related to a course, as well as the website are considered as collaborative tools to write ideas can support training in tech courses. According to the variety of communications media, today new challenge in educational 
technology is introduced and that is determination of the effects of overlapping and inconsistent content of the media in learning and engaging students in the content provided. Connectivism theory introduced by Siemens (2004) with an emphasis on the media connectivity can draw more comprehensive perspective for the effectiveness of each communication media. In the network learning pattern (Connectivism based approach) the action of knowing is assigned to the network (Siemens, 2004). In connectivism approach to learning, a network of knowledge is created to help learners replace updated content with old content. Also, during the process of learning it helps the students to be active (Siemens, 2006).

Student's engagement means their desire and need to participate in the learning process and promote higher-level of thinking to understand success (Bandaranaike and Willison, 2011). Connectivism is a staging perspective about individuals facing knowledge and reviewing it in the form of networking or ecology. Connectivism involves the following stages: awareness and receptivity, connection forming, contribution and engagement, pattern recognition, meaning making, praxis (Siemens, 2006). Since the present era is called the digital epoch, due to increased means of communication and students' dependence to the tools, learning environment should be removed from the traditional mode and in run accordance with the current era.

Connectivism theory is the learning theory in digital age and Siemens' goal (2006) is to apply technology capability in teaching and learning in the field of e-learning. And learning in connectivism theory based on informal processes, organizing in the network and supporting through electronic tools which causes increased collaborative activities, development of social-personal network, continuous practices of connection and development. Since connectivism theory is being developed, it seems essential to implement functional studies on efficiency test of the theory in objective conditions; therefore, the current study aims to investigate students' development and their engagement in the learning process through a quasi-experimental study and determining the effect of one of the communication media (website) in line with an educational purpose units and teaching a specific subject by applying the principles of connectivism theory. Therefore, it can be said the aim of the present study is to demonstrate the use of the theory in educational environments.

Education (in two levels: with communication media and without communications media in the traditional way) is considered as the independent variable and student's achievement in chemistry and students' engagement as the dependent variable. In this study the experimental group was taught through website and the control group was taught without website and in the usual way.

\section{RESEARCH THEORETICAL FOUNDATIONS \\ KNOWLEDGE AND LEARNING IN THE DIGITAL AGE}

Changes have little effects in society as long as they have no significant weight and strength. The concept of knowledge we have in mind, and consider it fixed, organized and defined by experts is changing and is gradually being replaced with more dynamic and multi-dimensional view (Siemens, 2006). These broad changes had a negative impact on knowledge and maintaining its previous structures. Libraries, schools, business centers have been under heavy pressure change as generators and the society consolidation (Siemens, 2006). New epistemology and ontology theories have been formed; we experience the life in a blending form; we see, think, and act in communication platform. Neither life nor knowledge is separate activity. Knowing is the rich and interwoven part of our universe (Siemens, 2006). In a general view, knowledge is historically defined or categorized in two forms: qualitatively or quantitatively. A new epistemology is needed which has more inclusive or at least develops the view to the today's world. Today, knowing and learning is defined by communication. The claim of connectivism is that learning is essentially networking process (Siemens, 2006).

\section{COMMUNICATING KNOWLEDGE AS THE FOUNDATION OF EPISTEMOLOGICAL THEORY}

connectivism was introduced by Stephen Downes. Features of an entity should be converted or redirected to the features of another entity so that they can be considered connected ones. The 
knowledge gained through such relationships is communication knowledge (Siemens, 2006). Communication knowledge network has 4 features:

1. Diversity: in the process of communicating knowledge as much as possible different points of view are included.

2. Autonomy: people arbitrarily and on the basis of knowledge, value and their decision, participate in the interaction or take command from some foreign institutions looking to expand a particular point of view.

3. Interactivity: the knowledge generated is the result of interaction between members. Also, it is merely collecting different perspectives.

4. Openness: there is a mechanism that allows a particular point of view to log in a system so that it can be heard to interact by others (Siemens, 2006).

\section{CONNECTIVISM THEORY}

Connectivism is a theory that describes how learning happens in digital age. This theory was first introduced by Siemens in 2004. The reason for this introduction was the fact that the new learning theory was for digital age because studies on traditional learning theories were conducted in a time when networking technologies had not been developed. At the time when the knowledge growth was high and technologies were replaced with people in many basic tasks, learning has been changed as well. Connectivism is rooted in the fact that decisions are based on foundations highly changing. In today's world, the age of knowledge is short and finishes as soon as possible. Educational courses have static nature; publishing date of textbooks comes back to the years before the time to use those (Siemens, 2006). Connectivism theory includes 9 basic principles as follow:

- Learning and knowledge need diverse perspectives to provide an overall and makes it possible to select the best approaches.

- Learning is the process of forming a network of specific nodes communication or information resources.

- Knowledge is located in networks.

- Knowledge may be living in non-human equipment and that Learning is facilitated by technology.

- More capacity of perception is more important than knowing what is known now.

- $\quad$ Learning and knowledge are permanent processes not a state or final product.

- Today, the ability to see relationships and identify patterns, and creation of meaning between fields, ideas and concepts, are individuals' skills fundamental.

- Updating (receiving correct and up to date knowledge) is the goal of all connectivism learning activities.

- Decision making is learning. Selecting what to learn and the meaning of input information are observed through an opening of a changing fact. While a response is correct today, it may be false tomorrow due to the changes occur in information atmosphere affecting decision (Siemens, 2006).

\section{STUDENT'S ENGAGEMENT}

Fredricks, Mccolskey, Meli, Mordica, Montrosse and Mooney (2011) knew the learner's engagement as cognitive interaction such as students' investment in learning stability against the challenges and using the depth instead of level strategy. Chapman (2003) also defined the learner's engagement as their willingness to participate in school activities including attendance, presentation of needed work 
and cooperating with teachers in classroom. Fletcher (2005) defined the learner's engagement as increasingly and significantly students' participation throughout the learning environment including participation in curriculum design, classroom management even school buildings. Connell (1990) involved emotional-conceptual aspects in and students' engagement and interaction. The emotional aspects are the sense of belonging, interest and enjoyment. Markwell (2007) knew students' engagement as their participation in the activities of a school, college, and university whose advantage is students' focus on curriculum studies. Bandaranik and Willson (2011) defined students' engagement as their willingness and needs to join in learning process and promote higher-level thinking to understand success.

\section{REVIEW OF LITERATURE}

Eskandari, Fardanesh and Sajadi (2009) indicated that connectivism theory as new partner of new learning theories not their replacements can have guidelines and many applications especially for elearning in web space 2.0. Garcia, Brown and Elbeltagi (2013) also in a study in the field of case study using collective blog based on connectivism theory for teaching and learning activities of the students studying in an institution in the UK indicated that from connectivism theory as learning theory in digital age, some of the theory elements can be regarded in group's engagement for the activities; however, this attitude is not seen in all groups engaging in the project.

Wang (2014) in his study showed that constructive instructional strategies play an important role in the high level of students' satisfaction and success of the course. When the course is implemented online, it is more effective than classroom. This study showed that using the online e-learning, courses can be carried out successfully and also causes more interactions and satisfaction of the students and teachers. Fonesca (2011) in his study about the learning experience on training camp provided by education system of Colombia in 2007 to create individual learning environments based on the emerging concepts such as e-learning of web 2.0 as well as connectivism, showed that designing educational technology workshops can be beneficial to develop lifelong learning and interaction on social networks that reflect the learning process. Mahmoudi, Fathiazar and Esfandiari (2009) studied the effect of students' active participation during teaching with their academic achievement. To investigate this, 60 classes of third grade in high school (30 classes with girl students, 30 classes with boy students) from three fields of literature and humanities, mathematical-physics and natural sciences from the five areas of the city of Tabriz were selected by multistage random sampling method then based on the Flenderz verbal communication analysis system, the frequency of ten factors were calculated. The results showed that there is no significant difference between boys and girls in the active participation in the teaching process, but it is positively correlated with academic achievement.

Staines and Lauchs (2013) also did research on student's engagement and the results showed that students use Web 2.0 technology primarily for social goals and not as a means to engage more with their scientific content. This study investigated a group of students who can use Facebook created by University of Technology in Brisbane, Queensland, Australia. The study also showed that students had less participation and interactions with site scientific content but their interaction abilities in analyzing non-scientific content and critical view toward non-scientific content were increased. This study also in alignment with other studies in this field showed that students use Facebook as a communication medium to enhance communication with their peers. In a study conducted by Happel, Park and Mcbride (2013) also open students response system was used to interact with students. Statistical population of the study was students in the eighth grade. The sample was selected in class of 16 students for algebra. Data analysis was performed through independent t-test and post-test were taken after 4 weeks of training. The results showed that the interaction of students who had used this system to teach algebra had a significant increase compared to the students who had passed the course with the traditional way.

\section{RESEARCH GOALS}


The aim of the present study was to investigate the use of communication tools based on connectivism theory on learners' engagement in high school, district 3, Tehran City in academic year of 2014-2015. It is evident that providing practical strategies are also in the context of this study.

\section{RESEARCH QUESTIONS AND HYPOTHESES RESEARCH QUESTIONS}

1. Do communication media affect students' academic achievement?

2. Do communication media affect students' engagement?

\section{RESEARCH HYPOTHESES}

H1: Communications media such as websites increase the students' engagement in the learning process.

$\mathrm{H} 2$ : Communications media such as websites have a positive impact on the academic achievement of students in chemistry.

\section{METHODOLOGY}

This study is quasi-experimental based on a design of pre-test and post-test with two experimental and control groups were implemented. The statistical population of the study consisted of the girl students studying as sophomore in high school, district 3, Bamdad e Parsi Educational Complex, Tehran City in academic year of 2014-2015. In this study, sampling method was "available sampling" and two 15students classes studying chemistry formed the experimental and control group. Before applying the independent variable in the experimental group, the questionnaire prepared by the researcher for chemistry lesson questionnaire was given to the two groups as pre-test. Also the survey test of students' engagement in high school was given to the two groups. The experimental group was treated by teaching chemistry through a website while the control group was treated by teaching chemistry traditionally without exposing to the website. The treatment continuously lasted for three days a week for two months. The two groups were again given the questionnaire prepared by the researcher and the survey test of students' engagement in high school as the training course finished. The following tools were used in the present study:

\section{SURVEY TEST OF STUDENTS' ENGAGEMENT IN HIGH SCHOOL}

The survey test of students' engagement in high school (2003) was designed by Evaluation Center at Indiana University in America and has been implemented from 2006 to 2013 on 400 thousand students in 40 states of America. This test has 31 items, each one has some options with a few sub options and this survey also assesses three emotional, behavioral, and cognitive dimensions and students' and school's interactions. Echeverria (2004) conducted the survey in five public schools in Virginia America and studied its internal consistency with coefficient Cronbach alpha. The results of this study revealed that Cronbach alpha coefficient of the three emotional, cognitive and behavioral dimensions respectively are $0.90,0.83$ and 0.81 . In the present study to determine the validity of the instrument it was first translated into Persian then to ensure the translation it was changed into English again, correctly translated from Farsi were translated into English and then its reliability based on the calculation of Cronbach alpha coefficient was 0.68 and in subtests were from 0.65 to 0.87 . The survey test of students' engagement in high school was implemented with 30 items for 35 minutes. For scoring, Likert scale from 1 to 4-point scoring was used to transform qualitative responses to quantitative responses. Finally the students were divided into 4 groups based on the scores obtained: students who have no interaction or engagement with school; students who have limited engagement; students who have moderate engagement; and students who have high engagement with school.The questionnaire included 20 multiple-choice questions on the second grade of high school chemistry. For the validity and reliability of the tools, first based on the target table of the chemistry lesson content, 50 multi-choice questions were designed and implemented on a sample of 50 students (outside of the sample).

After its implementation, 8 questions that had no certain features were omitted. Among the 42 questioned remained, 40 questions with suitable difficulty coefficient (0.557 to 0.731$)$ were chosen. 
After selecting the appropriate questions 5 chemistry teachers with more than 10 years of teaching experiences evaluated the questions and reported the proper questions. Cronbach alpha coefficient was 0.79 indicating suitable internal consistency. Then two sets of questions ( 20 questions each) were determined and implemented as pre-test in the experimental and control groups and their scores were calculated. The results of correlation coefficient of the test divided into two halves was equal to 0.81 . The correlation of post-test results with pre-test was 0.68 which is considered as proper validity for the chemistry achievement test made by the researcher. Finally the results of the academic achievement test and students' scores in chemistry were 0.53 indicating suitable construct validity of the researcher made test. The academic achievement test with 20 questions was conducted within 15 minutes and each question had one score. The students' scores were the correct responses they had and the test had no negative scores.

\section{WWW.CHEMICAL-SCHOOL.COM}

The above website has the properties including educational films, photos, PowerPoint presentations, questions sets and materials for third chapter of chemistry lesson. The experimental group had the opportunity to visit the site and use it. After compilation and designing the website, the material on the site were reviewed by three of the teachers as a group (by Focus Group method) and they correct the site content, appearance, problems and quality and finally confirmed the reliability of the materials in the website. The students in the experimental group were asked to visit the website using the username and password given to them and were taught chemistry through the website. Since connectivism theory has 9 basic principles, it was tried to apply them in designing the website. Afterwards, the students were asked to watch educational films and PowerPoint and at the end respond to relevant questions. Then the two experimental and control groups were given post-test in the classroom to assess their academic achievement and engagement.

\section{FINDINGS}

The mean and standard deviation of students' academic achievement in chemistry in both experimental and control groups in pre-test, post-test and follow-up were shown in table 1.

Table 1: Summary of descriptive findings of pre-test and post-test scores in experimental and control groups

\begin{tabular}{|l|c|c|c|c|c|c}
\hline & \multicolumn{2}{|c|}{ Pre-test } & \multicolumn{2}{c|}{ Post-test } & \multicolumn{2}{c}{ Follow up } \\
\hline & $\mathrm{M}$ & $\mathrm{SD}$ & $\mathrm{M}$ & $\mathrm{SD}$ & $\mathrm{M}$ & $\mathrm{SD}$ \\
\hline Experimental group & 16.67 & 1.718 & 18.67 & 0.816 & 18.33 & 0.724 \\
\hline Control group & 16.70 & 1.710 & 17.60 & 1.121 & & \\
\hline
\end{tabular}

According to the mean scores in experimental and control groups, it is observed that the post-test score was increased in the control group while this increase is very small compared to the differences in the experimental group. Although this difference may be due to training in two groups but it may also due to the repetition effect. In the follow up, a minor decrease in scores in the experimental group compared to post-test was seen. But again the follow-up scores differences compared to the pre-test scores is significant. To investigate the effect of training by communication media, ANOVA test with repeated measures were used. For the difference between this method and the traditional method of teaching without communication tool, the mixed ANOVA test between-within subjects were used and the result achieved because of the independent variable. The results indicate normal distribution of data in posttest. Shapiro-Wilk test was used to ensure normality (Table 2).

Table 2: Summary of Shapiro-Wilk test of data distribution normality 


\begin{tabular}{|l|c|c|c|c|}
\hline \multirow{2}{*}{} & \multicolumn{2}{|c|}{ Pre-test } & \multicolumn{2}{c}{ Post-test } \\
\cline { 2 - 5 } & $\mathrm{df}$ & sig & df & sig \\
\hline Experimental group & 15 & 0.357 & 15 & 0.059 \\
\hline Control group & 15 & 0.196 & 15 & 0.072 \\
\hline
\end{tabular}

According to Shapiro-Wilk test results it can be seen that all the sig in the groups are more than 0.05 and the results are not significant, thus the assumption of normality is not violated. Data distribution is normal and provides the use of parametric tests. To evaluate the effectiveness of training using communication tools (website) analysis of variance with repeated measures was used. The results indicated a significant effect for time with large effect sizes $(\mathrm{F}(13.2)=30.902, \mathrm{P}<0.0005$, Wilk's Lambda $=0.826$ ).

The results showed significant differences between the scores of chemistry lessons in different periods of time measured in the control group and the learning stability; therefore, teaching method using the communication tools had a positive and significant effect on learning chemistry with large effect sizes. To examine the differences between the groups, two by two comparison and subtracting the average results are shown in table 3 .

Table 3: Summary of groups' comparison

\begin{tabular}{|c|c|c|c|c}
\hline Time 1 & Time 2 & MD (1-2) & SE & sig \\
\hline Pre-test & Post-test & -2.000 & 0.276 & 0.000 \\
\hline & Follow up & -1.677 & 0.374 & 0.001 \\
\hline Post-test & Follow up & 0.333 & 0.159 & 0.166 \\
\hline
\end{tabular}

$* \mathrm{P}<0.001$

The results showed a significant difference between pretest and posttest mean scores, as well as pretest and follow-up (table 3). In other words, this difference reflects the effectiveness of training with communications tools that due to maintaining the results in the follow-up, it means that learning has been steady. Comparing post-test and follow-up results it can be seen though the results were had minor decrease, but there is no significant difference between these two stages, it also confirms the appropriate effectiveness of the independent variable. To examine the differences in effectiveness between the two educational methods, mixed ANOVA test of between-within subjects was implemented. Before analyzing the test results its hypothesis were determined.

To study the homogeneity of variance, which is the basic assumption of all ANOVA, first F Levene value in both times was measured. According to the results shown in table 2 the $\mathrm{F}$ value is not significant and the assumption of homogeneity of variances is not violated.

Table 4: studying the homogeneity of groups' variance in both pre and posttests stages 


\begin{tabular}{|c|c|c|c|c}
\hline & $\underline{F}$ & df1 & df2 & sig \\
\hline Pre-test & 0.014 & 1 & 28 & 0.908 \\
\hline Post-test & 1.105 & 1 & 28 & 0.302 \\
\hline
\end{tabular}

The main hypothesis of mixed ANOVA test of between-within subjects is the equality of correlations between several variables. For each variable level between subjects, the pattern of mutual correlations between variable levels within subjects should be the same. This hypothesis is tested using Box's M statistics and due to the sensitivity of the statistics more reliable level of alpha $(\mathrm{P}<0.001)$ is used. The results of Box statistics achieved (Box's $\mathrm{M}=3.844, \mathrm{~F}=1.182$ with degrees of freedom $\mathrm{df} 1=3$ and $\mathrm{df} 2=$ 141120.000 and $\operatorname{sig}=0.315$ ) indicates no violation from the main hypothesis, because due to sig= 0.315 which is more than 0.001 this statistics is not significant. Since there was no violation from the main hypothesis the mixed analysis of variance was performed between-within subjects (table 5).

Table 5: the results of mixed analysis of variance test between-within subjects (SPANOVA)

\begin{tabular}{|l|c|c|c|c|c|c}
\hline & SS & df & MS & F & sig & 2 \\
\hline Time & 30.817 & 1 & 30.817 & 67.062 & 0.000 & $0.705^{*}$ \\
\hline Time*group & 4.817 & 1 & 4.817 & 10.482 & 0.003 & $0.690^{*}$ \\
\hline Error & 12.867 & 28 & 0.460 & & & \\
\hline
\end{tabular}

$52 * \geq 0.14$

Eta coefficient equals 0.705 with the value of sig= 0.000 (in fact it means $\mathrm{P}<0.0005$ ); therefore, the effect of time is statistically significant and it can be concluded that there were significant differences in chemistry scores between two different periods of time. According to Cohen criterion (1998), that the effect size with more than 0.14 (explaining 14\% of the variance) is considered a large effect size, the effect size of 0.705 is large value therefore the main effect of time is significant. Before studying the main effects, the interaction effects should be evaluated to answer this question whether there has been the same change in two different groups' scores over time? For this purpose, Wilks' Lambda statistics from Multivariate test was used. According to the results, the interaction effect between time and group is significant (significant Level in Wilks' Lambda ( $\mathrm{sig}=0.03$ ) obtained which is less than the alpha level of 0.05). Interaction significance indicates that the effect of one variable (grouping) is affected by the level of second variable (time), despite the interaction between variables the diagram of interaction level between groups were investigated. Results showed an increase in both experimental and control groups scores in chemistry in two time periods of pretest and posttest, in fact grouping variable is affected by time but the increase in the experimental group with more linear gradient than the control group was carried out. The difference of pre and posttest scores in experimental group is more than control group. Therefore, $t$ test of the two independent groups was used to investigate the difference between the two educational methods. According to the results of $t$ test of the two independent groups $(\mathrm{sig}=0.006$ and $t=2.978)$ the difference significance of the two groups was shown. The following formula was used to determine the effect size of grouping.

$$
\mathfrak{f} 2=\frac{t^{2}}{t^{2}+(N 1+N 2-2)}
$$

By placing $t$ value in the formula of effect size, communication tools for the way to use was calculated 0.241. According to Cohen criterion (1998), the effect size of 0.241 is a little more. As a result, there was a significant difference in the two methods of education using communication tools (website) and traditional way and the method of teaching using communication tools has a significant effect on learning chemistry. 
Table 6: Summary of Shapiro-Wilk test of data distribution normality

\begin{tabular}{|l|c|c}
\hline & $\mathrm{df}$ & sig \\
\hline Experimental group & 15 & 0.469 \\
\hline Control group & 15 & $0.014^{*}$ \\
\hline$* \mathrm{P}<0.05$ & & \\
\hline
\end{tabular}

$* \mathrm{P}<0.05$

The significant results in control group showed violation in the normality hypothesis. Data distribution is not normal and the use of parametric tests is not provided, as a result, to compare the scores of students' engagement U Mann-Whitney nonparametric test was used. The results of U Mann-Whitney nonparametric test indicates no significant differences between the two groups ( sig= 0.345 and $\mathrm{Z}=0.975$ and $\mathrm{U}=89.000$ ). Although there is a difference between the mean of experimental group $(M=271.80$ and $S D=20.960)$ and the mean of control group $(M=275.33$ and $S D=24.383)$ but this difference is not significant. By reviewing the results of mixed analysis of variance test betweenwithin subjects and Eta coefficient obtained for the research variables as well as the results of $t$ test of the two independent groups the following points are important: the results of mixed analysis of variance test between-within subjects for the variable of time in both groups, teaching using

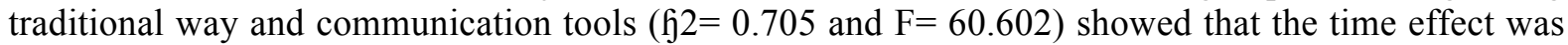
positive and significant. According to Cohen criterion the effect size of 0.705 is a little more therefore teaching through the two methods had positive and significant effects. Also, referring to the results associated with grouping and time it was seen that there was a significant interaction between the two variables resulted in the effectiveness of a variable effect (grouping) by a level of the second variable (time). For this reason the diagram was referred to interpret this interaction and it was seen in the experimental and control groups the scores were increased but this increase in experimental group had a positive and significant difference with control group. The $t$ test of the two independent groups was used to compare the difference of effectiveness of two methods and the results obtained confirmed the significant difference of the two educational methods. In addition to the difference between the two groups, by replacing the $t$ value mentioned in the formula, the effect size was calculated for teaching methods using communication tools, Eta coefficient for this method is 0.241 . According to Cohen criterion, the effect size of 0.241 is acceptable and a little more. According to the results, training using communication tools in addition to the significant difference with traditional instruction had positive and significant effect on learning chemistry. According to the results, no significant differences were seen in students' engagement in the two groups.

\section{DISCUSSION AND CONCLUSION}

This study was conducted with the aim to determine the effectiveness of communications media such as websites on students' academic achievement. The results of analysis of variance with repeated measures showed that training using communication tools is an effective method to increase learning and retention of the learned material in chemistry lessons. The results of the study are in line with Badri et al. (2010) who showed that the use of ICT in teaching chemistry plays an important role. The findings of the current study are in line with different studies by Ebrahimi et al. (2012); Eskandri et al. (2009); Chio and Wang (2008); Sarika and Caves (2008); Soltan Mohamadi (2010); Shahsavari Esfahani, Mosali Nejad and Sajanian (2010); Ghareh Baghi and Negoin (2009); Garsia et al. (2013) Gilbert (2011); Li, Krilavisios, Gang, Van and Man (2012); Miler (2011); Wang (2014) who confirmed the effectiveness of training using communication tools on increasing learning. Badrian et al. (2010) in a study confirmed that applying ICT in teaching chemistry plays an important role and the proposed pattern (field-oriented) is highly validated according to the teachers of chemistry and experts. The purpose of this study was to compare two methods of teaching, teaching by the use of communication tools and using traditional teaching method, also the effectiveness of the teaching methods conducted using mixed ANOVA test between-within subjects. According to the results obtained from the current study, it was seen that the teaching method using communication tools had more effectiveness compared to teaching without communication tools and its effectiveness was a 
little more and significant. The findings are in line with other studies by Ebrahimi et al. (2012); Banister et al. (2008); Hatami et al. (2009); Shahsavari Esfahani, et al. (2010); Karami et al. (2009); and Wang (2014).

In the study by Li et al. (2012) about using web to improve learning in Higher education, it was shown that teaching by the use of web facilitates the learning process; using social networks like Facebook to share content, experiences and news of an era, and a website as a common tool to write thoughts and beliefs can cause support in teaching tech courses. However, Carmen et al. (2009) carried out a research aimed at preparing teachers to use web-based teaching; they showed that although the teachers prepared the content of the web based on the materials written for learning before teaching, but they traditionally selected the learning materials in web and their order and sequence is the same as traditional method and had problems with leaning materials in web in terms of interaction and format.

To test another hypothesis of the study about the effectiveness of teaching using communication tools on students' engagement, the t test of the two independent groups was used. The results did not confirm this hypothesis. This result is similar to findings Estaniz et al. (2013), Garcia et al. (2013). Estaniz et al. (2013) in their study showed that students participate and interact less with established scientific content site, but their interaction ability to analyze unscientific content and communicate with peers increases. Some elements of connectivism theory as a theory of learning in the digital age could engage a number of students in the learning process, but interacting and engaging the most students did not materialize (Garcia et al., 2013). However, the results obtained are not in line with some other studies (Mahmoodi et al. (2009); Happel et al. 2013). Although the results obtained have been inconsistent in different studies and the findings of this study did not confirm the hypothesis mentioned, but according to the researcher's observations several points are noteworthy. Students' high motivation to learn, great the enthusiasm to start teaching despite the fact that the hours of training were in final hours when students were at school, being active while teaching, a great desire to use teaching methods using means of communication with other subjects in the curriculum showed students' engagement and interest in teaching which do not comply with their follow-up survey results.

Given that the survey was translated into Persian by researcher for the first time and also because of the lack of widespread implementation, for the validation of this survey, the inconsistent results with the researchers' observations requires thinking. Also, the use of communication media for effective teaching requires educational environments with the facilities necessary for students' use. Of course there are many factors in the failure to achieve this, including educator due to changes in teaching methods and lack of coordination with participatory training methods as well as the learners' constant presence in the classroom, space was not appropriate to engage the learner in the learning environment. Lack of adequate hardware facilities at school was among the limitations of the present study. The other limitations of the study, lack of high-speed Internet to perform the desired method of education, limiting the training for two months due to preventing the students to be treated for more time by school authorities, and lack of full access to the engagement survey guidelines because of the sanctions imposed were among the main limitations of the study. Also small statistical population and small sample size and implementing it on one material are the other limitations of this study which makes the generalization of its results possible by following the precautions. Conducting research as an experimental project, implementing on a sample with both sexes and more statistical population, making the students' engagement survey softer before conducting new research are the suggestions that by including them in future research, greater generalization capability with good results can be achieved.

\section{REFERENCES}

Ebrahimi, K., Mahdi, S., Karami, M., Ahanchian, M., Mozafari, P. (2014). Constructivist teaching impact on the satisfaction of participants in continuous web-based medical courses. New Approaches in Educational Management, 2 (5), 1 - 23. 
Eskandari, J., Fardanesh, H., Sajadi, M. (2009). Connectivism: in competition with alignment with other learning theories. Educational Psychology, 15 (5), 33-64.

Badrian, A., Honarparvar, B. , Naseri Azar, A. (2010). Design and validation of teaching patterns of field- orientation of chemistry based on ICT. Educational innovations, 9 (36), 101-125.

Hatami, CH., Mirzaei, A., Abbasi, J. (2009). Improving the quality of teaching chemistry concepts using concept maps. Learning Technology (IT and education), 3 (4), 281-296..

Siemens, Ch. (2013) Knowledge and learning: basics of connectivism theory. Translated by Eskandari, H. Tehran: Avaye No Publication.

Shahsavari, S., Mosali Nejad, L., Sobhanian, S. (2010). Comparing the effectiveness of using virtual and traditional teaching methods on students' skills circuit functionality. Hormozgan Medical Journal. 3 (14), 185-191.

Ghareh Baghi, SH., Soltan ohamadi, Z. (2010). Learning activities and discussions: a new approach in virtual education. Educational strategies. 1 (3), 35-39.

Karami Gazafi, A., Yonesi, J., Azizian, A. (2009). Comparing the effectiveness of chemistry laboratories to help develop educational software and traditional methods in students' academic achievement. Journal of Instructional Technology (IT education), 4 (2), 91-99.

Mahmoodi, F., Fathi Azar, E., Esfandiyari, R. (2009). Investigating the relationship of students' active participation in teaching with academic achievement. Journal of Psychology, 10 (3), 65 -82.

Bandaranaike, S., \& Willison, J. (2011).Proceedings of WACE $17^{\text {th }}$ worldconference on integrated education . 4-17 june 2011 . Philadelphia. PA.

Banister, S, Ross, C.\& Vannatta , R. (2008). The Impact of web 2.0 tools inthe Reading classroom.In k Mcferrin et al (Eds), proceedings of society for information technology \& teacher Education intermational conference (2008) (pp.36 17-3621).Chesapeake, VA Association for the Advan cement of computing in Education (AACE)

Connell, J.P.(1990).Context, self, and Action ; a motivational analysis of self-system processes acrosess the life-span. In D.cicchetti (Ed). The self in translition : infancy to child hood. Chicago. University of Chicago Press .

Fletcher, A.(2005).Guide to students as partners in school change. Olympia, WA: Soundout . Retrieved 2/20/08.

Garcia , E., Brown, M, \& Elbeltagi, I. (2013). Learning within a connectivist Educational Collective Blog Model : A case study of UK Higher Education Electronic Journal of e-learning., 11(3) , 253262.

Gilbert, B. (2011).Effectiveness of Virtual Learning.In Proceedings of World Conference on ELearning in Corporate, Government, Healthcare, and Higher Education 2011 (p. 1222). Chesapeake, VA: Association for the Advancement of Computing in Education (AACE).

Happel,L., Park, S. \& MC Bride, R. (2013). The Effects of student ResponseSystems (SRSs) on Eighth Grade pre-Algebra studens Achievemen andEngagement. In Society for Information Technology \& teacher Education International conference (Vol.2013, No.1, pp. 2122- 2129)

Lei, C.U., Krilavicius, T., Zhang, N., Wan, K., \& Man, K.L. (2012).Using Web2.0 tools to enhance learning in higher education: A case study in technologicaleducation.In Proceedings of the International Multi Conference of Engineers and Computer Scientists (Vo1.2).

Markwell , D. (2007).A large and liberal education: Higher education for the 21 St Century, Melbourne: Australian Schoarly publishing \& trinity college , university of Melbourne.

Miller , R.D.(2011).Developing 21 st century skils through the use of studentpersonal learning networks. Michigan. Proquest. Retrieved Septembr 7,2011 from http: //www/adsabs. harvard.edu.

Siemens , G. (2006, June). Networks :Revisiting objective / subjective. Retrieved September1 , 2006 , from http : // www. Conneclivism. Ca/ blog/ 67.

Stainers , Z.8 Lauchs, M. (2013).Students engagement with facebook in a university undergraduate policing unit .Australasian Jurnal of education Tecnology , 29(6). Australasian society for computers in tertiary education.

Wang, Y.D. (2014). Applying constructivist strategies to E-learning: A casestudy of a web Developmen course.International Journal on E-learning, 13(3) , 375-406. Chesapeake / VA: Association for the Advancement of computing in Education (AACE). 